\title{
Massive Open Online Courses (MOOCs) for Professional Teacher and Teacher Educator Development: A Case of TESSA MOOC in Kenya
}

\author{
Patriciah W. Wambugu \\ Department of Curriculum, Instruction \& Educational Management, Egerton University, Kenya
}

Copyright $\mathrm{C} 2018$ by authors, all rights reserved. Authors agree that this article remains permanently open access under the terms of the Creative Commons Attribution License 4.0 International License

\begin{abstract}
This study intends to present a bespoke teacher professional development MOOC designed by Teacher Education for Sub-Saharan Africa (TESSA) team that allows MOOCs to become a viable means offering cost-effective, quality professional teacher development. TESSA is a network of teachers and teacher educators, working to improve classroom teaching in Africa. TESSA MOOC is an innovative approach to capacity building for teacher educators and teachers across Africa. The study presents outputs of an evaluation of TESSA MOOC course undertaken by Kenyan teachers and teacher educators. The experiences of the participants were that the TESSA MOOC was a new but interesting, appealing and flexible course. In addition, the participants were able to learn from one another and what they learnt may impact on their pedagogical skills. Key challenges identified include difficulties in downloading of materials due to lack of internet connectivity and use of ICT phobia for learning. MOOCs represent an untapped potential for teacher professional development that can be a cost and resource effective means to deliver quality education to teachers and teacher educators. Therefore, the teachers and teacher educators may need to exploit this learner based TESSA MOOC to build capacity for teaching.
\end{abstract}

Keywords TESSA MOOC, Professional Teacher Development, Teacher, Teacher Educator

\section{Introduction}

Teacher professional development is the process of constantly strengthening professional attainment, broadening academic knowledge, enhancing the professional skills, and improving teaching ability. The $21^{\text {st }}$ century dynamics of the education systems emphasizes professional teacher quality due to the need on the increased number of students with diversified needs and the changing teaching technology (Hennessy, Haßler \& Hofmann [1]; Ji, Cao, [2] This therefore demands that teachers and teacher educators need to continually grow in the profession. The effectiveness of teacher quality depends largely on the extent to which their knowledge and skills are upgraded regularly. One of the key elements of teacher quality is the provision of adequate opportunities for personal growth and professional development through regular training (Avalos, [3]; Junaid, \& Maka, [4]. The traditional professional development courses where teachers go out of school to attend formal lectures, capacity building workshops and in-service courses are not addressing this need. This is due to the costs associated with professional teacher development, such as time, training and coaching, materials, equipment, and facilities, travel and university tuition and conference fees among others. There is need to have a more cost-effective way of training teachers and teacher educators for continued professional development.

MOOCs (Massive Online Open Courses) are freely available, short courses, delivered online, on a suitable platform. MOOCs are currently one of the latest educational revolutions a trending concept in education, which have proven a much-needed catalyst for the development of progressive programs that respond to the changing world. MOOCs therefore, represent an untapped potential for teacher professional development that may replace traditional educational courses Pope, [5], Suzannal $\&$ Myrick [6]. MOOCs have the potential to engage a large number of learners from different countries at any one time. They provide learners with the possibility to undertake activities drawing on a range of available resources and tools, while also offering participants opportunities for collaboration, and peer support. This study intends to present a bespoke teacher professional development MOOC designed by Teacher Education for Sub-Saharan Africa (TESSA) team that allows MOOCs to become a 
viable means offering cost-effective, quality professional teacher development. TESSA is a programme of activities designed to support teachers and teacher educators in developing more participatory approaches to teaching Anamuah-Mensah et al. [7]; Moon [8]; Murphy \& Wolfenden [9]. TESSA aims to improve the classroom practices of primary teachers and secondary science teachers in Africa through the provision of Open Educational Resources (OER) to support teachers in developing student-centred, participatory approaches. TESSA MOOC is an innovative approach to capacity building for teacher educators and teachers across Africa. The TESSA MOOC was designed as an open and free professional development opportunity for teacher educators in the African context. It was a short, taskoriented course that focused on the use of ICT and OER in teacher education - with a particular focus on TESSA.

\section{Objective}

The objective of this study was to examine the experiences of Kenyan teachers and teacher educators on TESSA MOOC and how effective the course was in their professional growth.

\section{Methodology}

This study was designed as an exploratory study aimed at understanding how the experiences of the sampled team of teachers and teacher educators on TESSA MOOC. TESSA MOOC materials were prepared by the TESSA team and then run on the Future-Learn platform (https://www.futurelearn.com/) which provides various tools to support learning. Before the start of the TESSA MOOC facilitators were trained to offer support to the participants. This was followed by the sensitization of the participants through posters, and visits to schools and universities. The interested participants were given the link to enable them register. The MOOC run for 4 weeks, and involved 3-4 hours of study each week. The study could be undertaken anytime during the week, at the convenience of the participants, on a range of mobile devices. Since this was an online course there were very many participants however this study focuses on the sampled primary and secondary schools and university. The sampled participants were in three groups these included; 15 teachers from one primary school(P), 16 teachers from one secondary school(S), 40 teacher Educators from one University (E) and a group of 19 teacher educators and 3 secondary school teachers from different institutions $(\mathrm{O})$. The evaluation was designed to find out how TESSA
MOOC impacted on the learning and practices of teachers and teacher educators, and the contribution of the MOOC to their learning. This involved meeting with the three teams for focused group discussions and use of questionnaires. It was clear with most participants that the MOOC was a new experience.

\section{Results and Discussion}

The majority of those who completed were in the group of 'other' while the primary school teachers were the least. This could be attributed with the timing of the MOOC, a time when the national exams were taking place.

Table 1 shows the distribution of those who expressed interest and their names were forward to TESSA team (UK), those who registered, completed and received certificates of completion. The table also shows those who did not complete and also the 5 who completed and have not yet received certificates.

Table 1. Distribution of the TESSA MOOC Participation

\begin{tabular}{|c|c|c|c|c|}
\hline Institution & $\begin{array}{c}\text { Number } \\
\text { interested }\end{array}$ & $\begin{array}{c}\text { Number } \\
\text { Registered }\end{array}$ & $\begin{array}{c}\text { Number } \\
\text { Completed } \\
\text { with } \\
\text { Certificate }\end{array}$ & $\begin{array}{c}\text { Percentage \% } \\
\text { of } \\
\text { completion }\end{array}$ \\
\hline University & 40 & 16 & 15 & 35.00 \\
\hline $\begin{array}{c}\text { Primary } \\
\text { School }\end{array}$ & 15 & 5 & 3 & 18.75 \\
\hline $\begin{array}{c}\text { Secondary } \\
\text { School }\end{array}$ & 19 & 12 & 7 & 46.67 \\
\hline Others & 23 & 23 & 22 & 95.65 \\
\hline Total & $\mathbf{9 4}$ & $\mathbf{5 6}$ & $\mathbf{4 7}$ & $\mathbf{5 0 . 0 0}$ \\
\hline
\end{tabular}

Table 1 shows that the performance was good especially for the group of "Others". This can be associated with the fact that the facilitator met the teams and after sensitization they agreed to form a TESSA MOOC WhatsApp group. This made it easy to support one another and the facilitator kept the team members informed on any communication from the MOOC Educators. This finding concurs with Davis [10] who found that Feedback System designed to promote learners' awareness through social comparison significantly increased course completion rates across different MOOC.

Those who did not have support group confessed that each straggled alone and it was difficult to complete. Those who never registered indicated that they were felt incompetent with ICT and the registration process was complicated and they gave up.

The participants were asked to answer what motivated them to learn. Figure 1 shows the responses. 


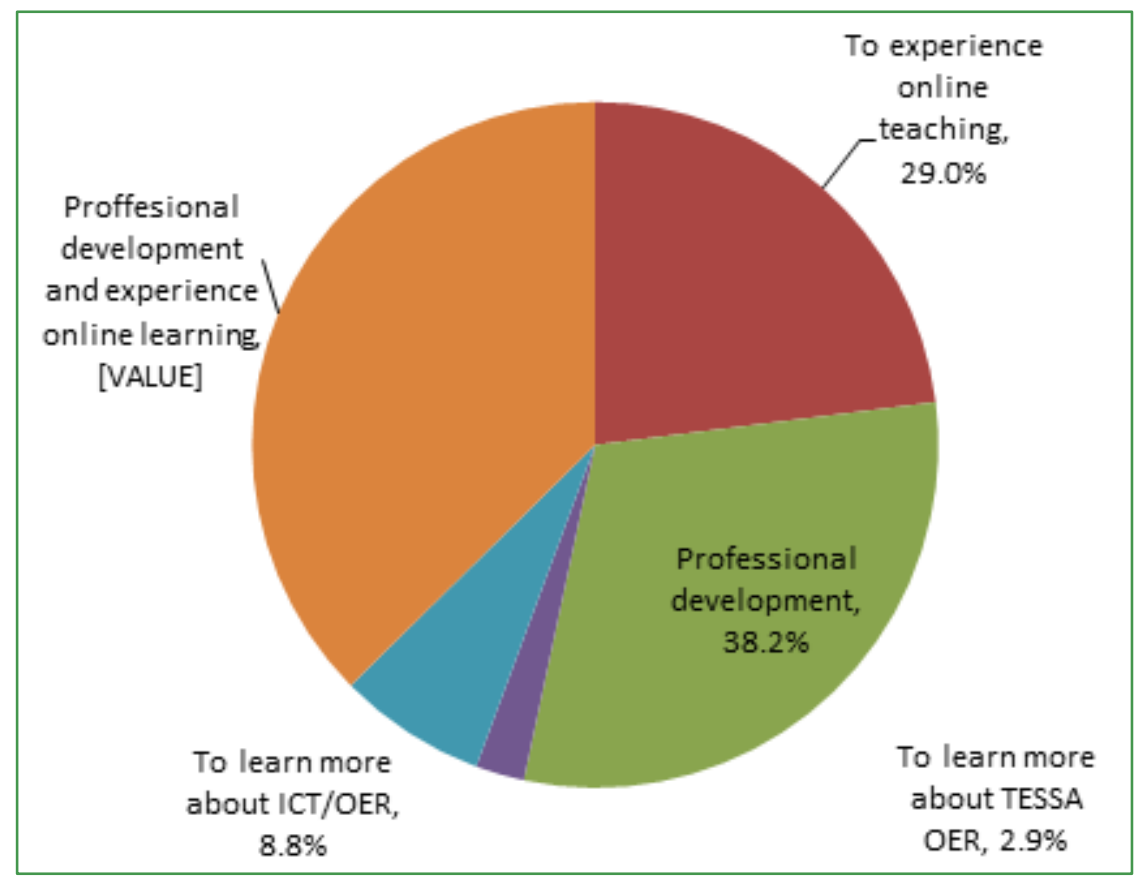

Figure 1. Motivation for studying the TESSA MOOC

Most participants were motivated to learn due the need for professional development and experience for online learning. This was in line with the findings from the group discussion where the respondents said that it now mandatory for teachers to show evidence for proffessional growth. The need to have an online experience may be attributed to the digital technology use in the classroom practices. This is in agreement with the findings of Hennessy, Haßler \& Hofmann [1]. Further in the focused group discussions it was revealed that school teachers were motivated to register for the TESSA MOOC as compared to the teacher educators. This could be attributed to the shift from the teacher centered to learner centered pedagogies and the requirement of integration of ICT in the learning process. School teachers in Kenya are now required to show continuous professional growth.

\section{Experiences of the Participants}

The group that never registered felt that they were very busy because of the timing of the MOOC and did not give the MOOC priority. In addition, they felt incompetent in ICT. Those who attempted and gave up indicated that that It was very difficult to work alone and got overwhelmed with other duties. The group that completed felt that though the MOOC was something new the course was very interesting, helpful and enhanced their ICT skills (Figure 2).

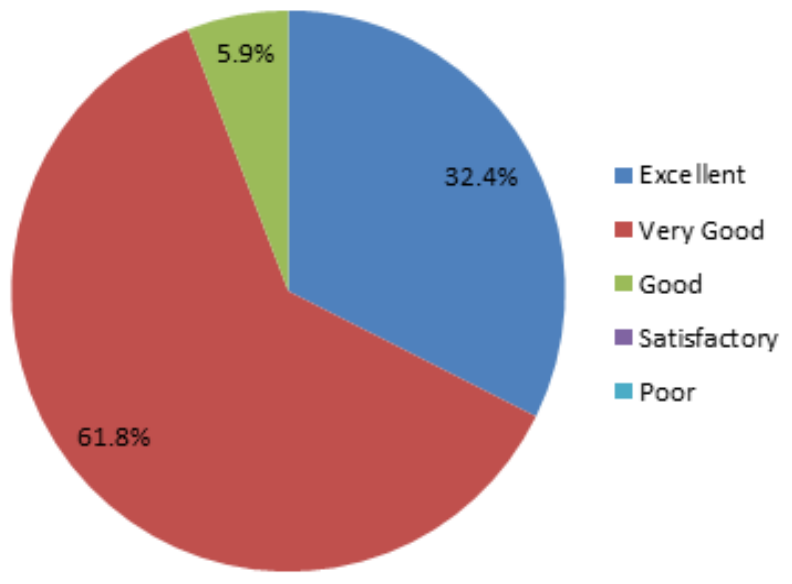

Figure 2. Overall assessment of the MOOC

The results shown in Figure 2 were complemented by the outcomes of the focused group discussions where the respondents indicated that the MOOC was very flexible since they would work at their own pace and very appealing because of the ease of using the mobile phone to learn. Additionally, the MOOC helped some overcome phobia of ICT. Further in the discussion, teacher educators rated the TESSA MOOC highly than the school teachers. They felt that the experiences acquired would help in the training of teachers in turn will benefit the learners in schools. The school teachers felt that the MOOC layout and content focused more on teacher educators although due the flexibility one could customize easily. 
The content of the MOOC for the four weeks was helpful in the areas of active learning, use of ICT to engage and motivate learners and handling of large classes Figure 3.

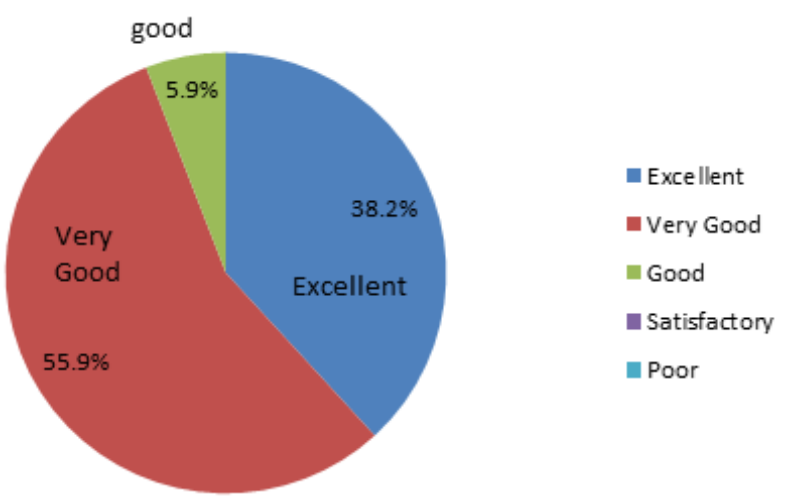

Figure 3. Rating of the content of the $\mathrm{MOOC}$ as a whole

The respondents were asked to indicate to what extent the MOOC increased their ability to lead improvements in teaching profession. Figures 4 indicate the responses.

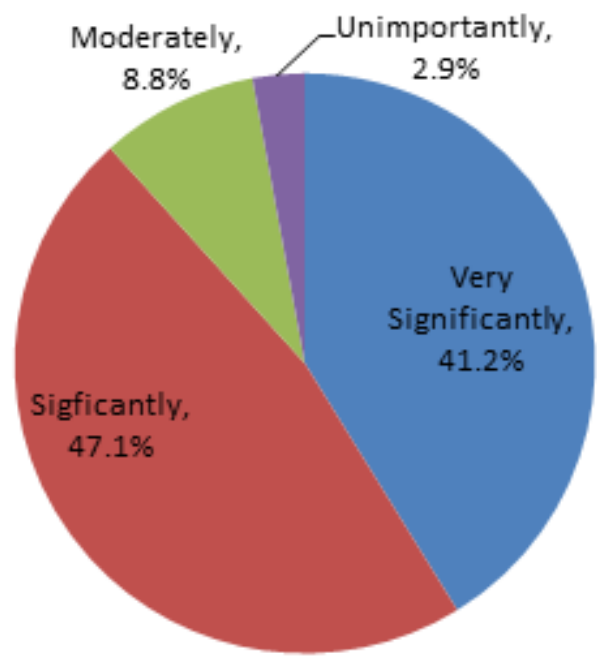

Figure 4. Extent the MOOC increased ability to lead improvements in teacher education

The MOOC significantly improved the ability of the participants in the teacher education in their institutions and also changed their perspective to plan and enact activities that promote teacher professional learning and pedagogy, particularly the teacher educators. Over $97 \%$ indicated that they will significantly use the information obtained through the MOOC in their work Figure 5. Both the teacher educators and school teachers in the focused group discussions equally felt that they would significantly use acquired knowledge in their work. This may be attributed to the paradigm shift towards active learning and integration of ICT in teaching.

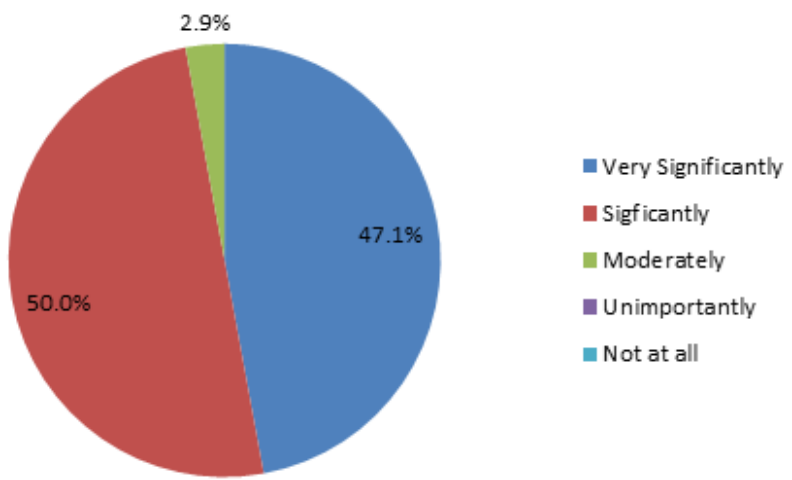

Figure 5. Extent of use of information obtained

The respondents indicated that they faced the challenge of no internet connectivity and therefore could not download the materials especially the videos. This delayed their work. The teachers were more affected because the TESSA MOOC was done when schools were on holiday session and therefore some of the teachers were in areas with no connectivity.

\section{Conclusions and Recommendations}

Teachers can receive high quality professional development from MOOC. The motivation to learn in the TESSA MOOC was the peer review and interactions among the participants and the self-regulated schedule with flexible start and stop dates. The TESSA MOOC may therefore help promote the professional development of teachers and teacher educators that can be upscaled for lifelong learning. MOOCs have the potential to develop digital skills to use OER which may enhance the professional development of teachers. In addition, visualizing a practical application of the course content increases participants' overall satisfaction. This is in agreement with the findings of Rivera \& Ramírez [11].

The participants were also awarded certificates of participation on successful completion of the course. There is need to have a way of recognition, validation, and accreditation of the MOOC learning. It is also recommended that more MOOCs may be designed to address the diverse needs of teacher and teacher educators especially in Sub-Saharan Africa.

\section{REFERENCES}

[1] Hennessy S., Haßler B. \& Hofmann R. Challenges and opportunities for teacher professional development interactive use of technology in African schools. Technology, Pedagogy and Education. 2015; 24 (5): 537-64). http://dx.doi.org/10.1080/1475939X.2015.1092466 
[2] Ji, Z., Cao, Y. A Prospective Study on the Application of MOOC in Teacher Professional Development in China. Universal Journal of Educational Research. 2016; 4(9): 2061-7. Available from: http://www.hrpub.org DOI: 10.13189/ujer.2016.040917

[3] Avalos, B. Teacher professional development in Teaching and Teacher Education over ten years. Teaching and Teacher Education. 2011; (27)10-20.

[4] Junaid, M. \& Maka, F. In-Service Teacher Education in Sub-Saharan Africa A Synthesis Report. 2015.

[5] Pope, J. Coursera to Offer MOOC Options Targeting Teacher Education. Community College Week. 2013; 25(21):1-10.

[6] Suzannal E. \& Myrick J.G. How MOOC instructors view the pedagogy and purposes of massive open online courses. Distance Education 2015.; 36(3): 295-311 Available from https:/www.tandfonline.com/doi/full/10.1080/01587919.20 15.1081736

[7] Anamuah-Mensah, J., Banks, F., Moon, B., Wolfenden, F. New modes of teacher and pre-service training and professional development, in: Moon, B. (Ed.), Teacher
Education and the Challenge of Development: A Global Analysis. 2013; 201-11.

[8] Moon, B., Creating new forms of teacher education: OER and the TESSA programme, in: Danaher, P., Umar, A. (Eds.), Teacher Education through Open and Distance Learning. Commonwealth of Learning, Toronto. 2010; 121-142.

[9] Murphy, P., \& Wolfenden F. Developing a pedagogy of mutuality in a capability approach: Teachers' experiences of using the Open Educational Resources (OER) of the Teacher Education in Sub-Sharan Africa (TESSA). International Journal of Educational Development. 2013; 33(3): 263 - 71.

[10] Davis D., Jivet I., Kizilcec R. F., Chen G. Hauff C. \& Houben G. Follow the Successful Crowd: Raising MOOC Completion Rates through Social Comparison at Scale. 2017; Proceedings of the Seventh International Learning Analytics \& Knowledge Conference Pages 454-463. Available from; https://dl.acm.org/citation.cfm?doid=3027385.3027411

[11] Rivera N. V; Ramírez M. S. Digital skills development: MOOCs as a tool for teacher training. 2015. ICERI 2015 Proceedings, Sevilla, Espana. 1-10. Available from https://repositorio.itesm.mx/bitstream/handle/11285/581442 